\title{
Effect of Geometric Nonlinearity on Deformation of Extra-long-span Cable-Stayed Bridges
}

\author{
Hengda Chen ${ }^{1, a}$, Sisi $\mathrm{Yao}^{1, \mathrm{~b}}$, Tao Song ${ }^{1, \mathrm{c}}$ and Fei Guo ${ }^{2, \mathrm{~d}}$ \\ 1 Department of Bridge Engineering, Chang'an University, Xi'an 710064, Shaanxi, China \\ 2 ZHE JIANG Provincial Institute of Communications Planning, Design and Research, Hangzhou \\ 310000, Zhejiang, China \\ a740554100@qq.com, b415533048@qq.com, 'c1332551096@qq.com, d1453000182@qq.com
}

\begin{abstract}
Keywords: Geometric Nonlinearity, Deformation, Main girder, Extra-long-span Cable-Stayed Bridges, Effect
\end{abstract}

Abstract. To fully take into account the effect of geometric nonlinearity on the deformation of extra-long-span cable-stayed bridges, a cable-stayed bridge with a main span of 780m was analyzed on the basis of the girder initial erection profile and three calculation modes, i.e., linearity, partially geometric nonlinearity without including cable sag, fully geometric nonlinearity, and the cantilever construction. The result shows that the geometric nonlinearity enhances distinctly with the increasing of cable length and cantilever length and cable sag stands out more prominently due to the three geometric nonlinearity factor. After the main girder closure, the geometric nonlinearity which caused by cable sag becomes slight. The research shows that it ensures the erection profile and final bridge geometry to take geometric nonlinearity into account.

\section{Introduction}

With the advent of calculation theory and calculation methods progress, the emergence of new materials and new construction methods, many extra-long-span cable-stayed bridges have been constructed or under construction in recent years.

There are many extra-long-span cable-stayed bridges whose main spans exceed 1000m in china, such as the Hong kong Stonecutters bridge with the main span of 1018m, Su tong with a main span of $1088 \mathrm{~m}$ and Shanghai Yangtze River bridge with the main span of 1092m.

As extra-long-span cable-stayed bridges span is increasing and the structure stiffness is decreasing, the geometric nonlinear problem emerges. The remarkable characters of extra-long-span cable-stayed bridges are the long cables and the soft structure, and the influences of geometric nonlinearity in both design period and construction period must be taken into consideration. [1-3]

\section{Geometric Nonlinearity on Deformation of Extra-long-span Cable-stayed Bridges}

The geometric nonlinear effect of extra-long-span cable-stayed bridges must be considered, such as cable sag, beam column, and large displacement. [4,5] Due to the increasing of extra-long cables , the cable sag effect is more obvious. As a "quasi truss" system of cable-stayed bridge, structural members subjected to both axial and bending moment are subjected to an interaction between two effects, which is beam column effect. As soft structure, extra-long-span cable-stayed bridges have character of significantly large deformation, which is the large displacement. When the final bridge geometry meets the desire design state, the erection profile needs to be determined.

The erection profile can be obtained by the method that the final bridge geometry superimposes the negative of bridge displacement in linear analysis; However, there is a relationship between final bridge geometry and initial erection profile in nonlinear analysis. The erection profile cannot be obtained by once calculation, and iteration method is needed. Figure 1 presents the iterative calculation process. 


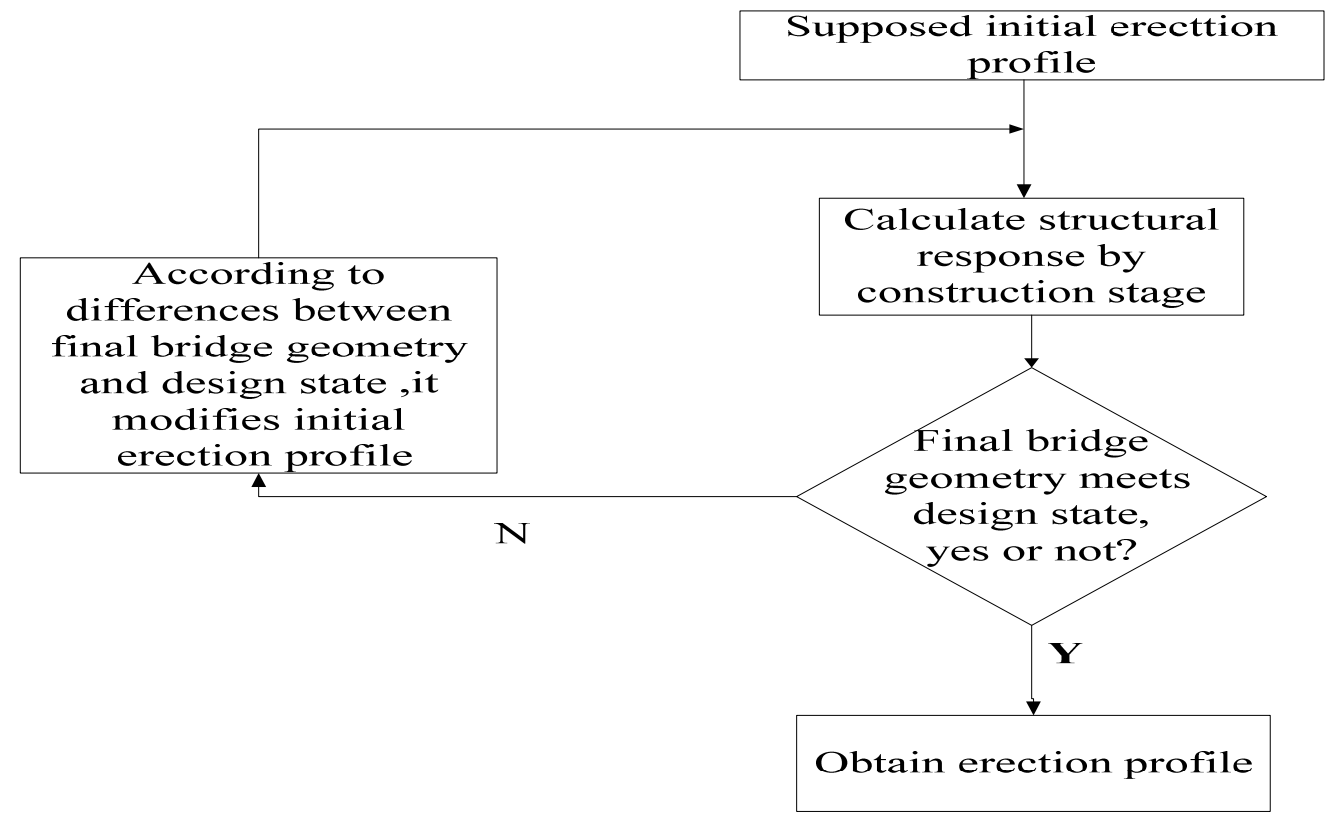

Figure1 . Iterative flow of erection profile

\section{Structural Modeling}

Main cable stayed bridge is a double-plane twin-pylon bridge with continuous span arrangement of $(70+285+780+285+70) \mathrm{m}$, as shown in Figure 2. One auxiliary pier and transitional pier are erected in each side span. The bridge girder is streamlined closed flat steel box girder. The diamond concrete pylons are about $224 \mathrm{~m}$ in height. The stay-cables are anchored inside steel boxes fixed to the concrete by shear studs at the pylon top. The stay-cable are arranged in double inclined cable planes with standard $15 \mathrm{~m}$. To reduce the effect of wind loads, the cable stay systems are made of the parallel wire stand consisting $7 \mathrm{~mm}$ wires. The selected permanent connection between the girder and the pylons is accomplished by nonlinear dampers.

The structural modeling keeps accordance with the plane construction schemes. Each of the stay-cable was divided into 8 sub-elements to consider cable sag — rather than approximate this effect - by using effective module of elasticity. Other interacting nonlinear effects such as beam-column effect, large displacement effect were also considered in the calculation. Creep and shrinkage effect were calculated according to the CEB/FIP90 code. The flexibility of the pylon foundation was modeled with consolation. Figure 3 presents the construction progress of each girder segment.

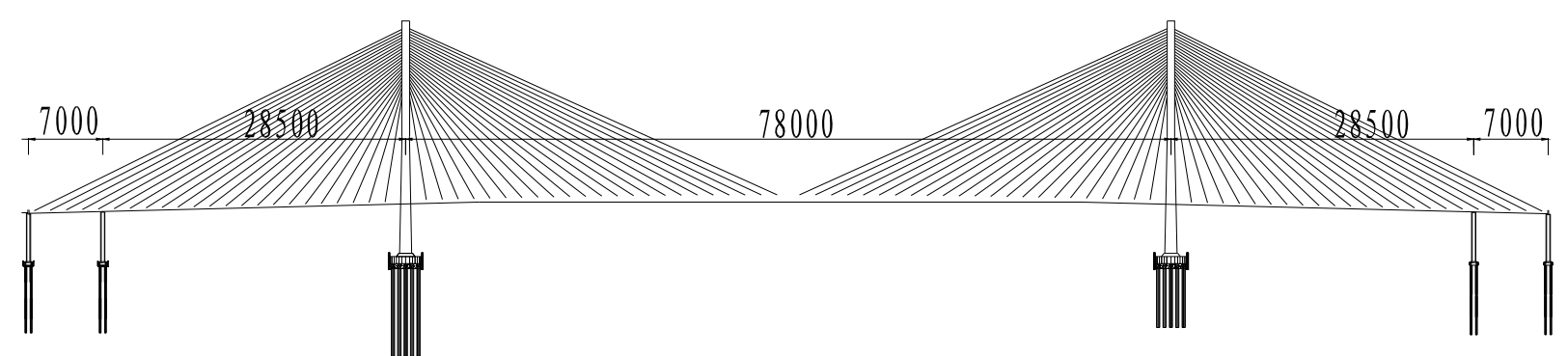

Figure 2. Elevtion view (unit:cm) 


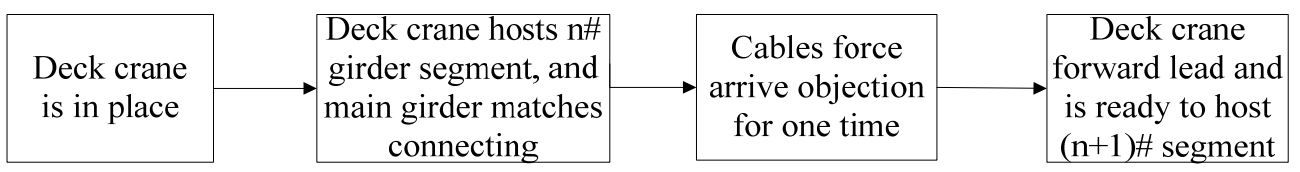

Figure3 . construction stage of n\# girder segment

\section{Analysis of Calculation Results}

Deformation of Main Girder During Cantilever Construction Stage. According to length of cable, 4 typical segments are selected, i.e.,5\#, 14\#, 21\#, 25\# girder segments. The characters of main girder are obtained by the method of calculation and analysis. Table 1 presents the girder segments and the length of cable and cantilever.

Table 1. Lengths of cable and cantilever for typical segments

\begin{tabular}{lcc}
\hline Girder segments & The length of cable/m & The length of cantilever $/ \mathrm{m}$ \\
\hline $5 \#$ & 137.40 & 102 \\
$13 \#$ & 237.99 & 222 \\
$21 \#$ & 350.86 & 342 \\
$25 \#$ & 409.19 & 387 \\
\hline
\end{tabular}

This gives: partially geometric nonlinearity:

$$
\lambda_{\text {partially }}=\frac{\delta_{\text {partially }}-\delta_{\text {fully }}}{\delta_{\text {fully }}}
$$

fully geometric nonlinearity:

$$
\lambda_{\text {fully }}=\frac{\delta_{\text {linearity }}-\delta_{\text {fully }}}{\delta_{\text {fully }}}
$$

Where $\lambda$ fully and $\lambda$ partially are respectively, partially geometric nonlinearity without including

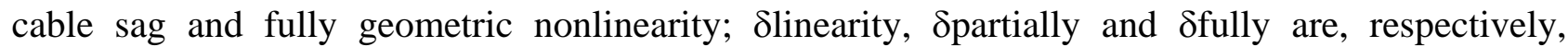
deformation of linearity, partially geometric nonlinearity without including cable sag and fully geometric nonlinearity.

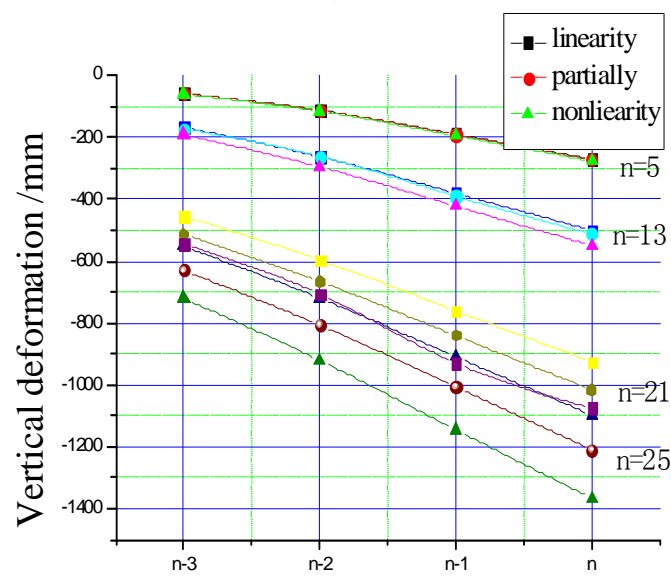

Segment number

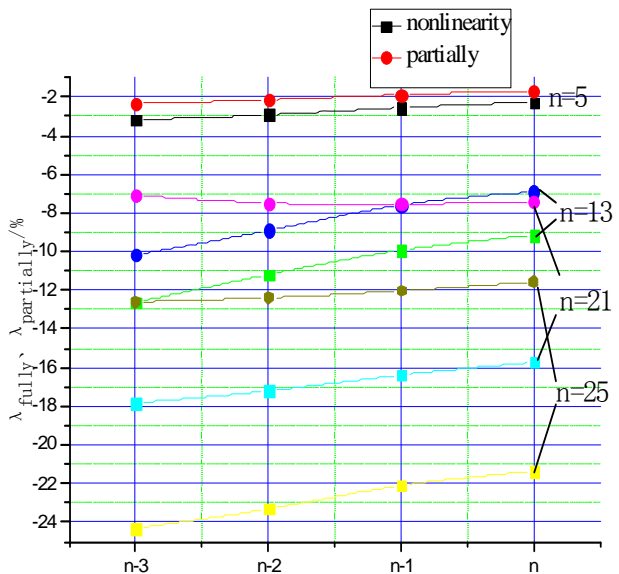

Segment number

Figure 4. Deformation and geometric nonlinear effect of girder cantilever construction From the results presented in Figure 4, the following results can be drawn:

(1) The vertical deformation of geometric nonlinear effect is about $3 \%$ in $5 \#$ girder segment's construction stage, about $13 \%$ in $13 \#$ 's, about 21 in 18\#'s and about $24 \%$ in $25 \#$ 's. The geometric nonlinear effect of deformation of 25\# girder segment is about 2 times of 13\# during the cantilever girder construction, the cable length of the former is about1.72 times of the latter and the cantilever length of the former is 1.74 times of the latter at this time.

(2) During the cantilever construction stage, the cable sag contribution for the geometric nonlinear deformation effect of $5 \#$ girder segment is nearly 0 ; of $13 \#$, only about $22 \%$; of $18 \#$, about $57 \%$; and 
of $25 \#$ about $48 \%$.As the main girder closure, the structure stiffness becomes large and the amount of the deformation of main girder geometric nonlinear effect deceases slightly.

Vertical Deformation of Girder Under Second Load.
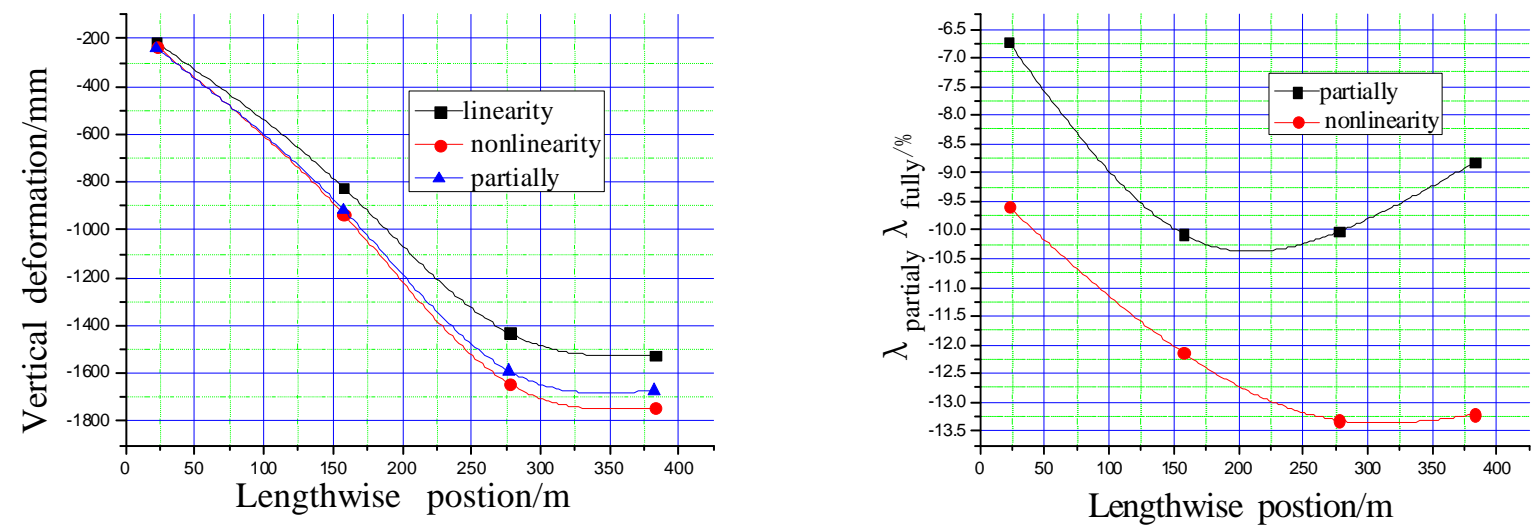

Figure 5. Deformation of girder under second load and geometric nonlinear effect

From the results presented in Figure 5, the following results can be drawn:

(1)The deformation of main girder becomes large under second load. The geometric nonlinear deformation is about $1700 \mathrm{~mm}$ while the geometric linear deformation is about $1500 \mathrm{~mm}$.

(2)After the closure of the main girder, the structure stiffness becomes larger. The geometric nonlinear effect account of main girder decreases, and the deformation of mid-span reduces $13 \%$ which mainly caused by the cable sag.

\section{Conclusions}

According to the study above, following conclusions can be drawn:

Vertical deformation of geometric nonlinear effect during construction stage is about $3 \%$ for $100 \mathrm{~m}$ cantilever, $13 \%$ for $220 \mathrm{~m}$ cantilever, $18 \%$ for $340 \mathrm{~m}$ cantilever and $24 \%$ for $340 \mathrm{~m}$ cantilever. Data illustrated above decrease slightly after the closure of the main girder.

During main girder cantilever construction and after its closure, the extra-long-span cable-stayed bridges has characters of large deformation and obvious nonlinear effects, especially the cable sag effect. There are great differences between linear analysis and nonlinear analysis results, so it is necessary to take the effect of geometric nonlinearity in design and construction into account.

\section{References}

[1] Wang $\mathrm{P} \quad \mathrm{H}$, Tseng $\mathrm{T} \mathrm{C}$, Yang $\mathrm{C} \mathrm{G}$. Initial shape of cable-stayed bridges [J].Computer\&Structures,1993, 47(1):111 123.

[2] YANG Xing-wang. Research on the nonlinear behavior of long-span cable-stayed bridge considering overall construction progress [D]. Chengdu: Southwest Jiao tong University, 2007. (In Chinese) [3] Y. Mishing, in: Diffusion Processes in Advanced Technological Materials, edtied by D. Gupta Noyes Publications/William Andrew Publising, Norwich, NY (2004), in press.

[3] Janjic D, Pircher M,Pircher H., " Optimization of Cable Tensioning in Cable-Stayed Bridges", Journal of Bridge Engineering, ASCE, v8, n3, pp131-137.

[4] J. F. Fleming. Nonlinear static analysis of cable-cable stayed bridges [J].Computer \&Structures,1979,10:621-635.

[5] Niels.J.Gimsing. Cable supported bridges concept \&design [M].3rd ed. JOHN WILEY\&SONS Ltd, 2012. 